Journal of Structural Engineering

Vol. 137, No. 3, March 2011, pp. 456-467,

(doi 10.1061/(ASCE)ST.1943-541X.0000074) 


\title{
Damage-Based Design Earthquake Loads for SDOF Inelastic Structures
}

\author{
Abbas Moustafa ${ }^{*}$ \\ Department of Civil Engineering, Graduate School of Engineering, Nagasaki University, Nagasaki 852-8521, Japan \\ Department of Civil Engineering, Faculty of Engineering, Minia University, Egypt 61111, Egypt
}

\begin{abstract}
This paper develops a new framework for modeling design earthquake loads for inelastic structures. Limited information on strong ground motions is assumed to be only available at the given site. The design earthquake acceleration is expressed as a Fourier series, with unknown amplitude and phase angle, modulated by an envelope function. The design earthquake is estimated by solving an inverse dynamic problem, using nonlinear programming techniques, such that the structure performance is minimized. At the same time, the design earthquake is constrained to the available information on past recorded ground motions. New measures of the structure performance that are based on energy concepts and damage indices are introduced in this paper. Specifically, the structural performance is quantified in terms of Park and Ang damage indices. Damage indices imply that the structure is damaged by a combination of repeated stress reversals and high stress excursions. Furthermore, the use of damage indices provides a measure on the structure damage level and thus a decision on necessary repair is possible. The material stress-strain relationship is modeled as either bilinear or elastic-plastic. The formulation is demonstrated by deriving the design earthquake loads for inelastic frame structures at a firm soil site. The damage spectra for the site are also established, which provide upper bounds of damage under possible future earthquakes.
\end{abstract}

CE Database subject headings: earthquake loads; inelastic structures; ductility ratio; hysteretic energy; damage indices; damage spectra; nonlinear optimization.

\section{Introduction}

The assessment of seismic performance of structures under future earthquakes is an important problem in earthquake engineering. The basic objective of the structural engineer is to design structures that are safe against possible future earthquakes and are economic at the same time. To achieve this goal, the following criteria should be fulfilled: (1) robust definition of earthquake 
ground motions for the site, (2) accurate mathematical model for the material behavior, and (3) reliable structural damage descriptors that describe accurately possible structural damage under seismic loads. The earthquake-resistant design of structures has been an active area of research for many decades. Early works have dealt with specifying earthquake loads in terms of the elastic and inelastic design response spectra for the site (e.g., Mahin and Bertero 1981, Newmark and Hall 1982, Riddell 1995), the time history of the ground acceleration (e.g., Bommer and Acevedo 2004) or using the theory of random vibrations (e.g., Kiureghian and Crempien 1989, Conte and Peng 1997). Hazard response spectra for the site have been also established by many researchers (e.g., Reiter 1990, McGuire 1995). The development of mathematical models to describe the hysteretic nonlinear behavior of the structure during earthquakes has been carried out by several researchers (e.g., Takeda et al., 1970, Otani 1981, Akiyama 1985). However, the inadequate performance of structures during recent earthquakes has motivated researchers to revise existing methods and to develop new methods for seismic-resistant design. This includes new design concepts, such as, energy-based design (e.g., Akiyama 1985, Goel 1997, Decanini and Mollaiodi 2001, Wong and Yang 2002), performance-based design (e.g., Park et al., 1985, Fajfar 1992, Fajfar and Krawinkler 1997, SEAOC 2000, Bozorgnia and Bertero 2004, Choi and Kim 2006) and optimum damper placement for seismic-resistant design (e.g., Nakashima et al., 1996, Yamaguchi and El-Abd 2003).

This paper develops a new framework for specifying robust design earthquake loads for seismic-resistant design of structures using the method of critical excitations. This method relies on the high uncertainty associated with the occurrence of earthquakes and their characteristics (e.g., time, location, magnitude, duration, frequency content, amplitude, etc.) and also on the safety requirements of important and lifeline structures (e.g., nuclear plants, storage tanks, industrial installations, etc.). A limited material on modeling critical earthquakes for nonlinear structures is available in the literature (e.g., Moustafa 2002, Abbas 2006, Takewaki 2002, 2007). Drenick and Iyengar provided early research thoughts on this subject. Iyengar (1972) computed critical seismic 
inputs for nonlinear Duffing oscillators by constraining the input energy. Drenick (1977) derived critical excitations for nonlinear systems in terms of the impulse response of the linearized system. Philippacopoulos and Wang (1984) expressed the critical input as a linear summation of recorded accelerograms and established critical inelastic response spectra for the site. This series representation, however, is questionable. Westermo (1985) used calculus of variation to show that the critical inputs for elastic-plastic systems are not harmonic. Recently, Takewaki (2001) used the equivalent linearization method to estimate critical probabilistic earthquakes for elastic-plastic structures that maximize the inter-storey drift. Abbas (2006) derived critical seismic loads for inelastic structures by maximizing the ductility ratio. Similarly, probabilistic critical earthquakes were computed for inelastic and parametrically excited structures by using FORM and response surface approximations (Sarkar 2003, Abbas and Manohar 2005, 2007).

From the above discussion it can be seen that most of the aforementioned research work is either conceptual, uses approximations in representing the ground motion or in calculating the structure response or is based on maximization of single response parameter. This paper avoids these approximations and introduces modern measures of structural damage to develop robust earthquake loads on inelastic structures. The structure performance is quantified using Park and Ang damage indices and thus a quantitative measure of the structure damage and necessary repair are possible.

\section{Response and Damage Characterization of Inelastic Structures under Earthquake Loads}

This section demonstrates briefly the seismic response analysis and energy quantification for SDOF inelastic structures under earthquake loads. Subsequently, the use of inelastic response parameters and energy absorbed by the structure in developing damage indices is explained.

\section{Dynamic Analysis of Inelastic Structures}

The equation of motion for a nonlinear SDOF structure under a single component of earthquake acceleration $\ddot{x}_{g}(t)$ is given as:

$$
m \ddot{x}(t)+c \dot{x}(t)+f_{s}(t)=-m \ddot{x}_{g}(t)
$$


where, $m, c$, are the mass and damping coefficient of the structure, respectively, $f_{s}(t)$ is the spring hysteretic restoring force, $x(t)$ is the structure displacement and dot indicates differentiation with respect to time. Fig. 1 depicts the relationship between the inelastic deformation and the spring hysteretic force for bilinear and elastic-plastic materials. Eq. (1) can be re-written as:

$$
\ddot{x}+2 \eta_{0} \omega_{0} \dot{x}+\omega_{0}^{2} x_{y} \bar{f}_{s}(t)=-\ddot{x}_{g}(t)
$$

Here, $\eta_{0}, \omega_{0}$ are pre-yield damping ratio and natural frequency, $x_{y}$ is the yield displacement and $\bar{f}_{s}(t)$ is the normalized hysteretic force. Eq. (2) can be further recast as:

$$
\ddot{\mu}(t)+2 \eta_{0} \omega_{0} \dot{\mu}(t)+\omega_{0}^{2} \bar{f}_{s}(t)=-\omega_{0}^{2} \frac{\ddot{x}_{g}(t)}{a_{y}}
$$

where, $\mu(t)=x(t) / x_{y}$ is the ductility ratio and $a_{y}=f_{y} / m$ is a constant that can be interpreted as the acceleration of the mass necessary to produce the yield force. The response of inelastic SDOF structures can be computed by solving the incremental form of Eq. (1) or (3) using numerical integration at discrete points of time. In this study, we use the Newmark $\beta$-method. For bilinear behavior, an iterative procedure is adopted to correct for approximations of the secant stiffness used from previous time step. The next subsection demonstrates the quantification of the earthquake input energy and associated energy dissipated by the structure.

\section{Earthquake Input Energy and Energy Dissipated by Inelastic Structures}

The energy balance for the SDOF inelastic structure can be obtained by multiplying Eq. (1) by the relative velocity $\dot{x}(\tau)$ and integrating, thus (Zahrah and Hall 1984, Akiyama 1985, Uang and Bertero 1990, Takewaki 2004, Kalkan and Kunnath 2008):

$$
\begin{aligned}
& \int_{0}^{t} m \ddot{x}(\tau) \dot{x}(\tau) d \tau+\int_{0}^{t} c \dot{x}^{2}(\tau) d \tau+\int_{0}^{t} f_{s}(\tau) \dot{x}(\tau) d \tau=-\int_{0}^{t} m \ddot{x}_{g}(\tau) \dot{x}(\tau) d \tau \\
& E_{K}(t)+E_{D}(t)+E_{S}(t)=E_{I}(t)
\end{aligned}
$$

Eq. (4) represents the relative energy terms (see, e.g., Uang and Bertero 1990, Kalkan and Kunnath 2008). Here $E_{I}(t)$ is the earthquake relative input energy to the structure since ground starts 
shaking until it comes to rest. $E_{K}(t)$ is the relative kinetic energy $\left(E_{K}(t)=m \dot{x}^{2}(t) / 2\right)$ and $E_{D}(t)$ is the energy absorbed by damping. The energy $E_{S}(t)$ represents the total relative energy absorbed by the spring and is composed of the recoverable elastic energy and the hysteretic cumulative plastic energy $E_{H}(t)$.

Note that, at the end of the earthquake duration the kinetic and elastic strain energies diminish. Thus, the earthquake input energy to the structure is dissipated by the hysteretic and the damping energies. The next section demonstrates the use of the response parameters and plastic energy in developing damage indices.

\section{Safety Assessment of Inelastic Structures using Damage Indices}

The literature on damage measures of structures under ground motions is vast (e.g., Cosenza et al., 1993, Ghobarah et al., 1999). Damage indices are based on either a single or combination of structural response parameters. Table 1 summarizes several damage measures that are based on a single response parameter (Powell and Allahabadi 1988, Cosenza et al., 1993). The first measure indicates the ultimate ductility produced during the ground shaking. Clearly, this measure does not incorporate any information on how the earthquake input energy is imparted on the structure nor how this energy is dissipated. Earthquake damage occurs not only due to the maximum deformation or ductility but is associated with the hysteretic energy dissipated by the structure as well. The definition of structural damage in terms of the ductility factor is therefore inadequate. The last three measures indicate the rate of the earthquake input energy to the structure (i.e., how fast $E_{I}$ is imparted by the earthquake and how fast it gets dissipated). Damage indices can be estimated by comparing the response parameters demanded by the earthquake with the structural capacities. Powell and Allahabadi (1988) proposed a damage index in terms of the ultimate ductility (capacity) $\mu_{u}$ and the maximum ductility attained during ground shaking $\mu_{\max }$ :

$$
D I_{\mu}=\frac{x_{\max }-x_{y}}{x_{u}-x_{y}}=\frac{\mu_{\max }-1}{\mu_{u}-1}
$$


However $D I_{\mu}$ does not include effects from hysteretic energy dissipation. Cosenza et al., (1993) and Fajfar (1992) proposed a damage index based on the structure hysteretic energy $E_{H}$ :

$$
D I_{H}=\frac{E_{H} /\left(f_{y} x_{y}\right)}{\mu_{u}-1}
$$

A robust damage measure should include not only the maximum response but the effect of repeated cyclic loading as well. Park and co-workers developed a simple damage index, given as (Park et al., 1985, Park and Ang 1985, Park et al., 1987):

$$
D I_{P A}=\frac{x_{\max }}{x_{u}}+\beta \frac{E_{H}}{f_{y} x_{u}}=\frac{\mu_{\max }}{\mu_{u}}+\beta \frac{E_{H}}{f_{y} x_{y} \mu_{u}}
$$

Here, $x_{\max }, E_{H}$ are the maximum displacement and dissipated hysteretic energy (excluding elastic energy) under the earthquake. Note that $x_{\max }$ is the maximum absolute value of the displacement response under ground motion. $x_{u}$ is the ultimate deformation capacity under monotonic loading and $\beta$ is a positive constant that weights the effect of cyclic loading on structural damage. Note that if $\beta=0$, the contribution to $D I_{P A}$ from cyclic loading is omitted.

The state of the structure damage is defined as: (a) repairable damage, when $D I_{P A}<0.40$, (b) damaged beyond repair, when $0.40 \leq D I_{P A}<1.0$, and (c) total or complete collapse, when $D I_{P A} \geq 1.0$. These criteria are based on calibration of $D I_{P A}$ against experimental results and field observations in earthquakes (Park et al., 1987). The Park and Ang damage index reveals that both maximum ductility and hysteretic energy dissipation contribute to the structure resistance during ground motions. In Eq. (7) damage is expressed as a linear combination of the damage caused by excessive deformation and that contributed by repeated cyclic loading effect. Note also that the quantities $x_{\max }, E_{H}$ depend on the loading history while the quantities $\beta, x_{u}, f_{y}$ are independent of the loading history and are determined from experimental tests. In this paper we adopt Park and Ang damage index in deriving the design earthquakes. The next section develops this formulation.

\section{Damage-Based Design Earthquake Loads for Inelastic Structures}


The derivation of critical earthquake loads for SDOF inelastic structures is developed in this section. The ground acceleration is represented as a product of a Fourier series and an envelope function:

$$
\ddot{x}_{g}(t)=e(t) \sum_{i=1}^{N_{f}} R_{i} \cos \left(\omega_{i} t-\varphi_{i}\right)=A_{0}\left[\exp \left(-\alpha_{1} t\right)-\exp \left(-\alpha_{2} t\right)\right] \sum_{i=1}^{N_{f}} R_{i} \cos \left(\omega_{i} t-\varphi_{i}\right)
$$

Here, $A_{0}$ is a scaling constant and the parameters $\alpha_{1}, \alpha_{2}$ impart the transient nature to $\ddot{x}_{g}(t)$. $R_{i}$ and $\varphi_{i}$ are $2 N_{f}$ unknown amplitudes and phase angles, respectively and $\omega_{i}, i=1,2, \ldots, N_{f}$ are the frequencies presented in the ground acceleration that are selected to span satisfactory the frequency range of $\ddot{x}_{g}(t)$. In constructing critical seismic inputs, the envelope function is taken to be fully known. The information on energy $E$, peak ground acceleration (PGA) $M_{l}$, peak ground velocity (PGV) $M_{2}$, peak ground displacement (PGD) $M_{3}$, upper bound Fourier amplitude spectra (UBFAS) $M_{4}(\omega)$, and lower bound Fourier amplitude spectra (LBFAS) $M_{5}(\omega)$ are also taken to be available which enables defining the following constraints (Abbas and Manohar 2002, Abbas 2006):

$$
\begin{aligned}
& {\left[\int_{0}^{\infty} \ddot{x}_{g}^{2}(t) d t\right]^{\frac{1}{2}} \leq E} \\
& \max _{0<t<\infty}\left|\ddot{x}_{g}(t)\right| \leq M_{1} \\
& \max _{0<t<\infty}\left|\dot{x}_{g}(t)\right| \leq M_{2} \\
& \max _{0<t<\infty}\left|x_{g}(t)\right| \leq M_{3} \\
& M_{5}(\omega) \leq\left|X_{g}(\omega)\right| \leq M_{4}(\omega)
\end{aligned}
$$

Here, $X_{g}(\omega)$ is the Fourier transform of $\ddot{x}_{g}(t)$. Note that the constraint on the earthquake energy is related to the Arias intensity (Arias 1970). On the other hand, the UBFAS and LBFAS constraints aim to replicate the frequency content and amplitude observed in past recorded accelerograms on the design earthquake. The ground velocity and displacement are obtained from Eq. (8) as follows:

$$
\dot{x}_{g}(t)=\sum_{i=1}^{N_{f}} \int_{0}^{t} R_{i} e(\tau) \cos \left(\omega_{i} \tau-\varphi_{i}\right) d \tau+C_{1} ; x_{g}(t)=\sum_{i=1}^{N_{f}} \int_{0}^{t} R_{i} e(\tau)(t-\tau) \cos \left(\omega_{i} \tau-\varphi_{i}\right) d \tau+C_{1} t+C_{2}
$$


Making use of the conditions $x_{g}(0)=0$ and $\lim _{t \rightarrow \infty} \dot{x}_{g}(t) \rightarrow 0$ (Shinozuka and Henry 1965), the constants in the above Eq. can be shown to be given as (Abbas and Manohar 2002, Abbas 2006):

$$
C_{2}=0 ; C_{1}=-\sum_{i=1}^{N_{f}} \int_{0}^{\infty} R_{i} e(\tau) \cos \left(\omega_{i} \tau-\varphi_{i}\right) d \tau
$$

The constraints of Eq. (9) can be expressed in terms of the variables $R_{i}, \varphi_{i}, i=1,2, \ldots, N_{f}$ as:

$$
\begin{aligned}
& {\left[A_{0}^{2} \sum_{m=1}^{N_{f}} \sum_{n=1}^{N_{f}} R_{m} R_{n} \int_{0}^{\infty}\left[\exp \left(-\alpha_{1} t\right)-\exp \left(-\alpha_{2} t\right)\right]^{2} \cos \left(\omega_{m} t-\varphi_{m}\right) \cos \left(\omega_{n} t-\varphi_{n}\right) d t\right]^{\frac{1}{2}} \leq E} \\
& \max _{0<t<\infty}\left|A_{0}\left[\exp \left(-\alpha_{1} t\right)-\exp \left(-\alpha_{2} t\right)\right]_{n=1}^{N_{f}} R_{n} \cos \left(\omega_{n} t-\varphi_{n}\right)\right| \leq M_{1} \\
& \max _{0<t<\infty} \mid A_{0} \sum_{n=1}^{N_{f} t} R_{n}\left[\exp \left(-\alpha_{1} \tau\right)-\exp \left(-\alpha_{2} \tau\right)\right] \cos \left(\omega_{n} \tau-\varphi_{n}\right) d \tau- \\
& A_{0} \sum_{n=1}^{N_{f}} \int_{0}^{\infty} R_{n}\left[\exp \left(-\alpha_{1} \tau\right)-\exp \left(-\alpha_{2} \tau\right)\right] \cos \left(\omega_{n} \tau-\varphi_{n}\right) d \tau \mid \leq M_{2} \\
& \max _{0<t<\infty} \mid A_{0} \sum_{n=1}^{N_{f} t} R_{n}\left[\exp \left(-\alpha_{1} \tau\right)-\exp \left(-\alpha_{2} \tau\right)\right](t-\tau) \cos \left(\omega_{n} \tau-\varphi_{n}\right) d \tau- \\
& A_{0} t \sum_{n=1}^{N_{f}} \int_{0}^{\infty} R_{n}\left[\exp \left(-\alpha_{1} \tau\right)-\exp \left(-\alpha_{2} \tau\right)\right] \cos \left(\omega_{n} \tau-\varphi_{n}\right) d \tau \mid \leq M_{3} \\
& M_{5}(\omega) \leq\left|A_{0}^{N_{f}} \sum_{n=1}^{\infty} \int_{0}^{\infty} R_{n}\left\{\exp \left[-\alpha_{1} \tau\right]-\exp \left[-\alpha_{2} \tau\right]\right\} \cos \left(\omega_{n} \tau-\varphi_{n}\right) \exp [-i \omega \tau] d \tau\right| \leq M_{4}(\omega)
\end{aligned}
$$

Here $i=\sqrt{-1}$. To quantify the constraints quantities $E, M_{1}, M_{2}, M_{3}, M_{4}(\omega)$, and $M_{5}(\omega)$ it is assumed that a set of $N_{r}$ earthquake records denoted by $\ddot{v}_{g i}(t), i=1,2, \ldots, N_{r}$ are available for the site under consideration or from other sites with similar geological soil conditions. The values of energy, PGA, PGV and PGD are obtained for each of these records. The highest of these values across all records define $E, M_{1}, M_{2}$ and $M_{3}$. The available records are further normalized such that the Arias intensity of each record is set to unity (i.e., $\left[\int_{0}^{\infty} \ddot{v}_{g i}^{2}(t) d t\right]^{1 / 2}=1$, Arias 1970), and are denoted by $\left\{\ddot{\bar{v}}_{g i}\right\}_{i=1}^{N_{r}}$. The bounds $M_{4}(\omega)$ and $M_{5}(\omega)$ are obtained as:

$$
M_{4}(\omega)=E \max _{1 \leq i \leq N_{r}}\left|\bar{V}_{g i}(\omega)\right| ; M_{5}(\omega)=E \min _{1 \leq i \leq N_{r}}\left|\bar{V}_{g i}(\omega)\right|
$$

Here $\bar{V}_{g i}(\omega), i=1,2, \ldots, N_{r}$ denotes the Fourier transform of the $i$ th normalized accelerogram $\ddot{v}_{g i}(t)$. The bound $M_{4}(\omega)$ has been considered earlier (Shinozuka 1970, Takewaki 2001, 2002). The lower bound was considered by Moustafa (2002) and Abbas and Manohar (2002). 
Finally, the problem of deriving critical earthquake loads for inelastic structures can be posed as determining the optimization variables $y=\left\{R_{1}, R_{2}, \ldots, R_{N_{f}}, \varphi_{1}, \varphi_{2}, \ldots, \varphi_{N_{f}}\right\}^{t}$ such that $D I_{P A}$ is maximized subjected to the constraints of Eq. (12). The solution to this nonlinear constrained optimization problem is tackled by using the sequential quadratic programming method (Arora 2004). The following convergence criteria are adopted:

$$
\left|f_{j}-f_{j-1}\right| \leq \varepsilon_{1} ;\left|y_{i, j}-y_{i, j-1}\right| \leq \varepsilon_{2}
$$

Herein, $f_{j}$ is the objective function at the $j$ th iteration, $y_{i, j}$ is the $i$ th optimization variable at the $j$ th iteration and $\varepsilon_{1}, \varepsilon_{2}$ are small quantities to be specified. The structure inelastic deformation is estimated using the Newmark $\beta$-method which is built as a subroutine inside the optimization program. The details of the procedure involved in the computation of the optimal earthquake and the associated damage index are shown in Fig. 2.

It may be emphasized that the quantities $\mu(t)$ and $E_{H}(t)$ do not reach their respective maxima at the same time. Therefore, the optimization is performed at discrete points of time and the optimal solution $y^{*}=\left[R_{1}^{*}, R_{2}^{*}, \ldots, R_{N_{f}}^{*}, \varphi_{1}^{*}, \varphi_{2}^{*}, \ldots, \varphi_{N_{f}}^{*}\right]^{t}$ is the one that produces the maximum $D I_{P A}$ across all time points. The critical earthquake loads are characterized in terms of the critical accelerations and associated damage indices, inelastic deformations and energy dissipated by the structure. The next section provides numerical illustrations for the formulation developed in this section.

In the numerical analysis, the constraints quantities $E, M_{1}, M_{2}, M_{3}, M_{4}(\omega)$, and $M_{5}(\omega)$ are estimated using past recorded earthquake data. These quantities are taken as the extreme values of the associated parameters across the set of past recorded ground motions. These parameters define the energy, PGA, PGV, PGD, and upper and lower bounds on the Fourier amplitude spectra of past recorded ground motions at the site under consideration or other sites with similar geological soil conditions. This approach is considered to be consistent with the aspirations of the ground motion models that are commonly used by engineers, which, basically aim to replicate some of the gross 
features of recorded motions, such as, amplitude, frequency content, nonstationarity trend, local soil amplification effects, and duration. It is of interest to note in this context that, predictive or physical models for ground motions, which take into account several details, such as, fault dimension, fault orientation, rupture velocity, magnitude of earthquake, attenuation, stress drop, density of the intervening medium, local soil condition and epicentral distance, have also been developed in the existing literature, mainly by seismologists (see, e.g., Brune 1970, Hanks and McGuire 1981, Boore 1983, Queck et al., 1990). In using these models, one needs to input values for a host of parameters and the success of the model depends upon how realistically this is done. It is possible to formulate the optimal earthquake models based on the latter class of models in which one can aim to optimize the parameters of the model so as to realize the least favorable conditions. It is important to note that the class of admissible functions, in the determination of critical excitations, in this case, becomes further constrained by the choice that one makes for the physical model. The approach adopted in this study, in this sense, is nonparametric in nature. A comparison of results based on this approach with those from 'model-based' approaches is of interest; however, these questions are not considered in the present study.

\section{Numerical Illustrations and Discussions}

\section{Bilinear Inelastic Frame Structure}

We consider a SDOF building frame with mass $9 \times 10^{3} \mathrm{~kg}$, initial stiffness $k_{0}=1.49 \times 10^{5} \mathrm{~N} / \mathrm{m}$ and viscous damping of 0.03 damping ratio. The initial natural frequency was computed as $4.07 \mathrm{rad} / \mathrm{s}$ and the strain hardening ratio is taken as 0.05 . These parameters are changed later to study their influence on the estimated optimal earthquake loads and corresponding inelastic deformations. The yield displacement is taken as $0.10 \mathrm{~m}$ and the structure is taken to start from rest. The objective function is adopted as the Park and Ang damage index $D I_{P A}$ given by Eq. (7). The parameters of the Newmark $\beta$-method are taken as $\delta=1 / 2 ; \alpha=1 / 6$ and $\Delta t=0.005 \mathrm{~s}$.

\section{Earthquake Data at the Site and Quantification of Constraints}


A set of 20 earthquake ground motions is used to quantify the constraint bounds $E, M_{1}, M_{2}, M_{3}$, $M_{4}(\omega)$ and $M_{5}(\omega)$ (COSMOS 2005). Table 2 provides information on these records (Abbas 2006). Based on numerical analyses of these records the constraints were computed as $E=4.17$ $\mathrm{m} / \mathrm{s}^{1.5}, M_{1}=4.63 \mathrm{~m} / \mathrm{s}^{2}(0.47 \mathrm{~g}), M_{2}=0.60 \mathrm{~m} / \mathrm{s}$ and $M_{3}=0.15 \mathrm{~m}$. The average dominant frequency of the ground accelerations was about $1.65 \mathrm{~Hz}$. The envelope parameters were taken as $A_{0}=2.17$, $\alpha_{1}=0.13$, and $\alpha_{2}=0.50$. The convergence limits $\varepsilon_{1}, \varepsilon_{2}$ were taken as $10^{-6}$ and the convergence criterion on the secant stiffness is taken as $10^{-3} \mathrm{~N} / \mathrm{m}$.

The frequency content for $\ddot{x}_{g}(t)$ is taken as (0.1-25) Hz. Additionally, in distributing the frequencies $\omega_{i}, i=1,2, \ldots, N_{f}$ in the interval $(0.1,25)$, it was found advantageous to select some of these $\omega_{i}$ to coincide with the natural frequency of the elastic structure and also to place relatively more points within the modal half-power bandwidth.

The constraint scenarios considered in deriving the optimal earthquake inputs are listed in Table 3. The constrained nonlinear optimization problem is tackled using the sequential quadratic optimization algorithm 'fmincon' of the Matlab optimization toolbox (Caleman et al., 1999). In the numerical calculations, alternative initial starting solutions, within the feasible region, were examined and were found to lead to the same optimal solution. To select the number of frequency terms $N_{f}$ a parametric study was carried out and $N_{f}=51$ was found to give satisfactory results. Fig. 3 depicts the influence of the frequency terms $N_{f}$ on the convergence of the objective function for constraints scenarios 1 and 4 (see Table 3).

\section{Results and Discussions}

The numerical results obtained are presented in Figs 4-9 and Table 4. Fig. 4 shows results for constraint scenario 1 and similar results for case 4 are shown in Fig. 5. Each of these figures shows the Fourier amplitude spectrum of the optimal ground acceleration, the inelastic deformation, the hysteretic force and the energy dissipated by the structure. Fig. 6 shows the time history of the 
ground acceleration and velocity for cases 1 and 4 . Based on extensive analyses of the numerical results, the following observations are made:

1. The frequency content and Fourier amplitude of the design earthquake are strongly dependent on the constraints imposed (see Table 3). If available information on earthquake data is limited to the total energy and PGA, the design input is narrow band (highly resonant) and the structure deformation is conservative (see Fig. 4 and Table 4). Furthermore, most of the power of the Fourier amplitude is concentrated at a frequency close to the natural frequency of the elastic structure. This amplitude gets shifted away from the natural frequency towards a higher frequency when the strain hardening ratio increases. The Fourier amplitudes at other frequencies are low and uniformly distributed. The results of this constraint scenario match well with earlier work reported by this author for elastic-plastic structures (Abbas 2006) and also by Takewaki (2001) on probabilistic earthquake inputs for elastic-plastic structures. This result, however, is substantially different from that for the elastic structure where all power of the acceleration amplitude is concentrated around $\omega_{0}$ with no amplitude at other frequencies (Abbas and Manohar 2002). Additional constraints on the Fourier amplitude spectra (see Table 3) force the Fourier amplitude of the optimal acceleration to get distributed across other frequencies. The critical acceleration possesses a dominant frequency that is close to the average dominant frequency observed in past records (see Fig. 5). The realism of the earthquake input is also evident from the maximum damage index it produces. For instance, the damage index for case 4 is 0.37 which is substantially smaller than 1.15 for case 1 (Table 4 ). The constraints on PGV and PGD were not found to be significant in producing realistic critical inputs compared to the constraints on UBFAS and LBFAS. Also, the realism of the optimal acceleration for case 4 can be examined by comparing the Fourier amplitude spectra and frequency content of the design acceleration (Figs 4,5) with the Fourier amplitude spectra of past recorded earthquakes (Fig. 7). It may be emphasized that while the constraint scenario 1 leads to pulse-like ground motion, 
such scenario was in deed observed during some of the recent earthquakes (e.g., 1971 San Fernando, 1985 Mexico, and 1995 Hyogoken-Nanbu earthquakes). Resonant or pulse-like earthquakes are also observable in near-field ground motion with directivity focusing, known as forward- and backward-directivity ground motion, which resemble fault-parallel and fault-normal components (Housner and Hudson 1958, Kalkan and Kunnath 2006, He and Agrawal 2008 and Moustafa 2008). The realism of optimal earthquake loads can be also examined by comparing maximum response from optimal accelerations with those from past recorded ground motions. Thus, the maximum ductility factor of the structure from the design earthquake is about 3.9 (case 1) and 2.6 (case 4) times that from the Hyogoken-Nanbu earthquake and is 2.7 (case 1) and 1.5 (case 4) times that from the San Fernando earthquake.

2. To examine the effect of the strain hardening ratio on the design earthquake acceleration computed, limited studies were carried out. The value of $\alpha$ was changed and the critical input was determined by solving a new optimization problem. Namely, $\alpha$ was taken as $0.20,0.10$, 0.05 , and 0.01 . The strain hardening ratio was not seen to significantly influence the frequency content of the critical earthquake input. It was observed, however, that the inelastic structure with lower values of $\alpha$ yields more frequently compared to the same system with higher $\alpha$ values. Accordingly, the cumulative hysteretic energy dissipated was observed to decrease for higher values of $\alpha$ (Fig. 8(a)). This feature is particularly remarkable at the end of the earthquake duration. It was also observed that the results on critical earthquake accelerations for bilinear inelastic structure with $\alpha=0.01$ are close to those for the elastic-plastic structure (Abbas 2006).

3. To investigate the influence of the damping ratio on the computed design earthquake load, limited studies were carried out. The damping ratio was changed (namely, 0.01, 0.03 and 0.05 ) while all other parameters were kept unchanged. The critical earthquake is computed by solving a new optimization problem for each case. The effect of the change in $\eta_{0}$ was seen to be 
similar to that due to $\alpha$. In other words, the value of the damping ratio was not seen to significantly influence the frequency content of the earthquake acceleration. It was observed, however, that the ductility ratio and the maximum inelastic deformation for the structure decrease for higher damping ratios. Thus, the ductility ratio decreases to 2.43 when the damping ratio is taken as 0.05 while the ductility ratio increases to 2.89 when the damping ratio reduces to 0.01 . It was also observed that the inelastic structure with higher damping ratio dissipates more energy through damping compared with the same structure with lower damping ratio (see Fig. 8(b)). The damage index also reduces when the damping ratio increases.

4. To assess the structure safety, Eq. (7) was used to estimate the damage index of the structure subjected to the critical earthquake load. We first examine the effect of the parameter $\beta$ on the damage index. Based on experimental tests, it was reported that $\beta$ ranges between 0.05 and 0.20 with an average value of 0.15 as suggested by Park et al., (1987). Fig. 9(a) shows the influence of $\beta$ on the damage index. To study the effect of the initial natural frequency of the structure on the damage index, the structure stiffness was varied while keeping all other parameters unchanged and the critical earthquake was computed for each case. Subsequently, the value of $D I_{P A}$ was calculated for each case. In the numerical calculations $\beta$ was taken as 0.15 and $x_{\max }, \mu_{\max }$ are taken as $0.10 \mathrm{~m}$ and 2.64 , respectively. The value of $\mu_{u}$ was taken as 6 in Fig. 9(a) and 8 in Fig. 9(b). It was found that the damage index for the structure with initial natural frequency smaller than 1.65 is higher than 0.40 and thus either total collapse or damage beyond repair of the structure is expected. The value of $D I_{P A}$ for the structure with $\omega_{0}$ greater than about $1.70 \mathrm{~Hz}$ is less than 0.40 and thus the structure does not experience total damage but repairable damage. This observation is consistent since the site dominant frequency is around $1.65 \mathrm{~Hz}$ and since the Fourier amplitude of the ground acceleration is seen to be located in the stiff side of the initial frequency of the inelastic structure. 
It may be noted that the numerical illustrations of the formulation developed in this paper were demonstrated for simple structures modeled as SDOF systems with bilinear and elastic-plastic force-deformation laws. The application of the proposed method to MDOF structures and the use of more detailed degradation models (e.g., trilinear degradation, Takeda and Clough models) need to be investigated. Additionally, in this paper Park and Ang damage index has been used to assess the structure performance. It may be emphasized that this damage index has some limitations, which have been discussed by Mehanny and Deierlein (2000) and Bozorgenia and Bertero (2003). Among these drawbacks are: (1) its weak cumulative component for practical cases given the typical dominance of the peak displacement term over the accumulated energy term, (2) its format using a linear combination of deformation and energy in spite of the obvious nonlinearity of the problem and the inter-dependence of the two quantities, and (3) its lack of considering the loading sequence effect in the cumulative energy term. Furthermore, when $E_{H}=0$ (elastic behavior), the value of $D I_{P A}$ should be zero. However, the value of $D I_{P A}$ computed from Eq. (7) will be greater than zero. Similarly, when the system reaches its maximum monotonic deformation, while $D I_{P A}$ should be 1.0, however, Eq. (7) leads to $D I_{P A}$ greater than 1.0. Chai et al (1995) proposed modification to $D I_{P A}$ to correct for the second drawback only. The study, also, examined experimentally the implication of the energy-based linear damage model of $D I_{P A}$. Despite the drawbacks of $D I_{P A}$, it has been extensively used by many researchers, mainly due to its simplicity and the extensive calibration against experimentally observed seismic structural damage during earthquakes (mainly for reinforced concrete structures). Bozorgenia and Bertero (2003) proposed two improved damage indices that overcome some of the drawbacks associated with $D I_{P A}$.

In this paper, the optimal earthquakes that maximize the structural damage were obtained using deterministic methods. The design earthquake loads can be formulated based on hazard analysis using probability of occurrence which provides a powerful alternative to the methodology developed in this paper. 


\section{Concluding Remarks}

This paper developed a methodology for specifying earthquake ground motions as design inputs for inelastic structures at sites having limited earthquake data. New damage descriptors are introduced in deriving optimal earthquake loads. Specifically, the structural damage is quantified in terms of Park and Ang damage indices. Damage indices are mathematical models for quantitative description of the damage state of the structure and they correlate well with actual damage displayed during earthquakes. It is believed that the quantification of structural damage in terms of damage indices is of substantial importance in deriving critical earthquake loads for inelastic structures. This is because damage indices imply that the structure is damaged by a combination of repeated stress reversals and high stress excursions. The quantification of the structure damage in terms of damage indices makes it possible to assess the safety of the structure and provides an idea on necessary repair.

The design earthquake is estimated based on available information using inverse dynamic analysis and nonlinear optimization methods. It was seen that if available information is limited to the energy and PGA, the resulting earthquake is highly resonant and produces conservative deformation. On the other hand, if extra information on the Fourier amplitude spectra is available, more realistic earthquakes are obtained (in terms of frequency content, amplitude, inelastic deformations and damage indices they produce). The influences of the strain hardening and damping ratios on the estimated design loads were also studied. Critical damage spectra for the site were also established. These spectra provide an upper bound on structural damage and necessary repair under possible future earthquakes. The formulation developed in this paper was demonstrated for frame structures modeled as SDOF systems. The application of the proposed method to MDOF structures is currently under investigation. In this case, the global damage index of the structure is defined in terms of a weighted function of the damage indices for the individual structural members. 


\section{Acknowledgements}

The author thanks three anonymous reviewers for their careful reading of the paper and insightful comments they made. This research work is partly supported by research funds from the Japanese Society for the Promotion of Science. The support is gratefully acknowledged.

\section{Notation}

The following symbols are used in this paper:

$$
\begin{aligned}
& a_{y} \quad=\text { ratio of yield force to mass of the structure; } \\
& c \text { = damping coefficient; } \\
& C_{1}, C_{2}=\text { constants; } \\
& D I=\text { damage index; } \\
& D I_{P A}=\text { Ang and Park damage index; } \\
& e(t) \quad=\text { envelope function; } \\
& E=\text { Arias intensity (energy) of ground acceleration; } \\
& E_{D}=\text { energy dissipated by damping; } \\
& E_{H}=\text { hysteretic energy; } \\
& E_{I}=\text { earthquake input relative energy; } \\
& E_{k}=\text { kinetic energy; } \\
& E_{S}=\text { strain energy } \\
& f_{s}(t)=\text { hysteretic restoring force; } \\
& k_{0}, k_{p}=\text { pre-yield and post-yield stiffness; } \\
& \alpha=\text { strain hardening ratio; } \\
& m \text { = mass; } \\
& N_{f} \quad=\text { number of frequencies; } \\
& M_{1}, M_{2}, M_{3} \text { = peak ground acceleration, velocity and displacement, respectively; } \\
& M_{4}(\omega), M_{5}(\omega)=\text { lower and upper Fourier amplitude spectra, respectively; } \\
& t \text { = time; } \\
& \tau=\text { dummy variable indicating time; } \\
& A_{0}, \alpha_{1}, \alpha_{2}, \beta=\text { positive constants; } \\
& \ddot{x}, \dot{x}, x=\text { acceleration, velocity and displacement responses of SDOF system, } \\
& \text { respectively; } \\
& \ddot{x}_{g}, \dot{x}_{g}, x_{g}=\text { ground acceleration, velocity and displacement, respectively; } \\
& \eta_{0}, \omega_{0}=\text { damping ratio and natural frequency of elastic structure; } \\
& \mu \text { ductility ratio; } \\
& f_{y}, x_{y}=\text { yield force and yield displacement, respectively; } \\
& R_{i}, \varphi_{i}=\text { ith amplitude and phase angle of the ground acceleration; } \\
& x_{\max }=\text { maximum displacement of inelastic structure; } \\
& x_{u}, \mu_{u}=\text { ultimate displacement and ductility under monotonic load; } \\
& \varepsilon_{1}, \varepsilon_{2}=\text { small positive constants }
\end{aligned}
$$




\section{References}

Abbas, A.M. (2006). "Critical seismic load inputs for simple inelastic structures." J. Sound Vib., 296, 949-967.

Abbas, A.M., Manohar, C.S. (2002). "Investigations into critical earthquake load models within deterministic and probabilistic frameworks.” Earthq. Eng. Struc. Dyn., 31, 813-832.

Abbas, A.M., Manohar, C.S. (2005). "Reliability-based critical earthquake load models. Part 2: Nonlinear structures.” J. Sound Vib., 287, 883-900.

Abbas, A.M., Manohar, C.S. (2007). "Reliability-based vector nonstationary random critical earthquake excitations for parametrically excited systems. Structural Safety, 29, 32-48.

Akiyama, H. (1985). Earthquake-resistant limit-state design for buildings, University of Tokyo Press, Tokyo.

Arias, A. (1970). A measure of earthquake intensity: seismic design of nuclear power plants, Cambridge, MA: MIT press, 438-468.

Arora, J.S. (2004). Introduction to optimum design, Elsevier Academic Press, San Diego.

Bommer, J.J., Acevedo, A.B. (2004). "The use of real earthquake accelerograms as input to dynamic analysis.” J. Earthq. Eng., 1, 43-91.

Boore DM. (1983). "Stochastic simulation of high-frequency ground motions based on seismological models of the radiated spectra.” Bul. Seis. Soc. Am. 1983;73:1865-94.

Bozorgnia, Y, Bertero, V.V. (eds) (2004). Earthquake engineering, CRC Press, NY.

Bozorgenia, Y., Bertero, V.V. (2003) "Damage spectra: Characteristics and applications to seismic risk reduction.” J. Struct. Eng., 1129(4), 1330-1340.

Brune, JN. (1970). "Tectonic stress and the spectra of seismic shear waves from earthquakes.” $J$. Geoph. Res. 75, 4997-5009.

Caleman, T., Branch, M.A., and Grace, A. (1999). Optimization toolbox for the use with Matlab: user's guide, The MATH WORKS Inc., USA. 
Chai, Y.H., Romstad, K.M., Bird, S.M. (1995). "Energy-based linear damage model for high-intensity seismic loading." J. Struct. Eng., 121(5), 857-864.

Choi, H., Kim, J. (2006). "Energy-based design of buckling-restrained braced frames using hysteretic energy spectrum.” Eng. Struct., 28, 304-311.

Conte, J.P., Peng, B.F. (1997). "Fully nonstationary analytical earthquake ground motion model.” J. Eng. Mech., 123, 15-24.

Cosenza, C., Manfredi, G., Ramasco, R. (1993). "The use of damage functionals in earthquake engineering: a comparison between different methods.” Earthq. Eng. Struc. Dyn. 22, 855-868.

COSMOS (2005). Consortium organizations for strong-motion observation systems, http://db.cosmos-eq.org/scripts/default.plx.

Decanini, L.D., Mollaioli, F. (2001) “An energy-based methodology for the assessment of seismic demand.”So. Dyn. Earthq. Eng., 21, 113-137.

Drenick, R.F. (1977). “The critical excitation of nonlinear systems.” J. Appl. Mech., 18, 333-336.

Fajfar, P. (1992). “Equivalent ductility factors, taking into account low-cyclic fatigue.” Earthq. Eng. Struc. Dyn. 21: 837-848.

Fajfar, P., Krawinklere H. (1997). Seismic design methodologies for the next generation of codes, Rotterdam, Balkema.

Ghobara, A., Abou-Elfath, H., Biddah, A. (1999). "Response-based damage assessment of structures.” Earthq. Eng. Struc. Dyn., 28, 79-104.

Goel, R.K. (1997). "Seismic response of asymmetric systems: energy-based approach.” J. Struct. Eng., 123(11), 1444-1453.

Hanks, TG, McGuire RK. (1981). "The character of high frequency ground motions based on seismic shear waves.” Bul. Seis. Soc. Am. 71:2071-95.

Housner, G.W. and Hudson, D.E. (1958). “The Port Hueneme earthquake of March 18, 1957.” Bull. Seism. Soc. Amer., 48, 163-168. 
He, W.-L., Agrawal, A.K. (2008). “Analytical model of ground motion pulses for the design and assessment of seismic protective systems.” J. Struct. Eng., 134 (7), 1177-88.

Iyengar, R.N. (1972). "Worst inputs and a bound on the highest peak statistics of a class of non-linear systems.” J. Sound Vib., 25, 29-37.

Kalkan, E., and Kunnath, S.K., (2006). "Effects of fling step and forward directivity on seismic response of buildings." Earthq. Spec., 22(2), 367-390.

Kalkan, E., and Kunnath, S.K., (2008). "Relevance of absolute and relative energy content in seismic evaluation of structures.” Adv. Struct. Eng., 11(1), 1-18.

Kiureghian, A.D., Crempien, J. (1989). "An evolutionary model for earthquake ground motion.” Struct. Saf., 6, 235-246.

Mahin, S.A., Bertero, V.V. (1981). “An evaluation of inelastic seismic design spectra.” J. Struct. Div., 107(ST9): 1777-1795.

McGuire, R.K. (1995). "Probabilistic seismic hazard analysis and design earthquake: closing the loop.” Bull. Seism. Soc. Am., 85, 1275-1284.

Mehanny, S.S., Deierlein, G.G. (2000). Modeling of assessment of seismic performance of composite frames with reinforced concrete columns and steel beams. Report No. 135, The John Blume Earthquake Research Center, Stanford University.

Moustafa, A. (2002). "Deterministic/Reliability-based critical earthquake load models for linear/nonlinear engineering structures", $\mathrm{Ph}$. D. thesis, Department of Civil Engineering, Indian Institute of Science, Bangalore, India.

Moustafa, A. (2008). "Discussion of analytical model of ground motion pulses for the design and assessment of seismic protective systems.” J. Struct. Eng., MS No. STENG-341, in press.

Nakashima, M., Saburi, K., Tsuji, B. (1996). "Energy input and dissipation behavior of structures with hysteretic dampers." Earth. Eng. Struct. Dyn. 25, 483-496. 
Newmark, N.M., Hall, W.J. (1982). “Earthquake spectra and design, Monograph”, Earthq. Eng. Res. Inst. (EERI).

Otani, S. (1981). "Hysteretic models of reinforced concrete for earthquake response analysis." J. Fac. Eng., University of Tokyo, 36(2), 407-441.

Park, Y.J., Ang, A H-S. (1985). "Mechanistic seismic damage model for reinforced concrete.” J. Struct. Eng., 111(4), 722-739.

Park, Y.J., Ang, A H-S., Wen, Y.K. (1985). "Seismic damage analysis of reinforced concrete buildings.” J. Struct. Eng., 111(4), 740-757.

Park, Y.J., Ang, AH-S., Wen, Y.K. (1987). “Damage-limiting aseismic design of buildings.” Earthq. Spec., 3(1), 1-26.

Powell, G.H., Allahabadi, R. (1988). "Seismic damage predictions by deterministic methods: concepts and procedures.” Earthq. Eng. Struc. Dyn. 16, 719-734.

Quek ST, Teo YP, Balendra T. (1990). "Non-stationary structural response with evolutionary spectra using seismological input model.” Earthq. Eng. Struct. Dyn. 19:275-88.

Riddell, F. (1995). "Inelastic design spectra accounting for soil conditions." Earthq. Eng. Struc. Dyn. 24: 1491-1510.

Reiter, L. (1990). Earthquake hazard analysis, New York, Columbia University Press.

Philippacopoulos, A.J., Wang, P.C. (1984). “Seismic inputs for nonlinear structures.” J. Eng. Mech., $110,828-836$.

SEAOC, Vision Committee (2002). "Performance based seismic design engineering." Sacramento, USA: Structural Engineers Association of California (SEAOC) Report.

Sarkar, A. (2003). "Linear stochastic dynamical system under uncertain load: inverse reliability analysis.” J. Eng. Mech., 129(6), 665-671.

Shinozuka, M., (1970). "Maximum structural response to seismic excitations.” J. Eng. Mech., 96, $729-738$. 
Shinozuka, M. and Henry, L., (1965). "Random vibration of a beam column.” J. Eng. Mech., 91, 123-143.

Takeda, T., Sozen, M.A., Nielsen, N. (1970). "Reinforced concrete response to simulated earthquakes.” J. Struct. Div., 96(ST12), 2557-2573.

Takewaki, I. (2002). "Seismic critical excitation method for robust design: A review." J. Struct. Eng., 128, 665-672.

Takewaki, I. (2007). Critical excitation methods in earthquake engineering, Elsevier Science.

Takewaki, I. (2004). “Bound of earthquake input energy” J. Struct. Eng., 130, 1289-1297.

Takewaki, I. (2001). "Probabilistic critical excitation for MDOF elastic-plastic structures on compliant ground." Earthq. Eng. Struct. Dyn., 30, 1345-1360.

Wong, K.K.F., Yong, R. (2002). "Earthquake response and energy evaluation of inelastic structures.” J. Eng. Mech., 128(3), 308-317.

Westermo, B.D. (1985). “The critical excitation and response of simple dynamic systems.” J. Sound Vib., 100, 233-242.

Yamaguchi, H., El-Abd, A. (2003). "Effect of energy input characteristics on hysteretic damper efficiency." Earthq. Eng. Struct. Dyn. 32, 827-843.

Zahrah, T.F., Hall, W.J. (1984). "Earthquake energy absorption in sdof structures.” J. Struct. Eng., $110,1757-1772$.

Uang, C-M., Bertero, V.V. (1990). "Evaluation of seismic energy in structures.” Earth. Eng. Struct. Dyn., 19, 77-90. 


\section{List of Figures}

Fig. 1: (a) Force-displacement relation for nonlinear materials

Fig. 2: Flowchart for deriving optimal earthquake loads

Fig. 3: Convergence of objective function in terms of frequency terms $N_{f}$ (a) Case 1 (b) Case 4

Fig. 4: Optimal earthquake input and associated structural responses for case 1 (a) Fourier amplitude of the ground acceleration (b) Inelastic deformation (c) Hysteretic restoring force (d) Dissipated energy

Fig. 5: Optimal earthquake input and associated structural responses for case 4 (a) Fourier amplitude of the ground acceleration (b) Inelastic deformation (c) Hysteretic restoring force (d) Dissipated energy

Fig. 6: Optimal earthquake acceleration and velocity (a) Case 1 (b) Case 4

Fig. 7: Fourier spectra of recorded earthquakes (a) San Fernando 1971 (b) Hyogoken-Nanbu 1995

Fig. 8: (a) Effect of strain hardening ratio on dissipated yield energy (b) Effect of damping on dissipated damping energy

Fig. 9 (a) Effect of the value of $\beta$ on the damage index (b) damage spectra for inelastic SDOF structures 
Table 1: Response descriptors for inelastic buildings under earthquake ground motion

\begin{tabular}{|c|c|c|}
\hline S. No. & Response parameter & Definition \\
\hline 1 & Maximum ductility & $\mu_{\max }=\max _{0 \leq t \leq t}\left|\frac{x(t)}{x_{y}}\right|$ \\
\hline 2 & Number of yield reversals & Number of times velocity changes sign \\
\hline 3 & Maximum normalized plastic deformation range & $\Delta \bar{x}_{p, i}=\max _{0 \leq t \leq t_{f}}\left|\frac{\Delta u_{p, i}}{x_{y}}\right|$ \\
\hline 4 & Normalized cumulative ductility & $\mu_{a c .}=\sum_{i=1}^{N} \frac{\left|\Delta x_{p, i}\right|}{x_{y}}+1$ \\
\hline 5 & Residual (permanent) ductility & $\mu_{r e s}=\left|\frac{x\left(t_{f}\right)}{x_{y}}\right|$ \\
\hline 6 & Normalized earthquake input energy & $\bar{E}_{I}=\frac{1}{f_{y} x_{y}} \int_{0}^{t} E_{I}(t) d t$ \\
\hline 7 & Normalized total hysteretic energy dissipated & $\bar{E}_{H}=\frac{1}{f_{y} x_{y}} \int_{0}^{t_{f}} E_{H}(t) d t$ \\
\hline 8 & Ratio of total hysteretic energy to input energy & $r_{E}=\frac{\bar{E}_{H}}{\bar{E}_{I}}$ \\
\hline 9 & Maximum rate of normalized input energy & $P_{I, \max }=\frac{1}{f_{y} x_{y}} \max _{0 \leq t \leq t_{f}}\left[\frac{d E_{I}(t)}{d t}\right]$ \\
\hline 10 & Maximum rate of normalized damping energy & $P_{D, \max }=\frac{1}{f_{y} x_{y}} \max _{0 \leq t \leq t_{f}}\left[\frac{d E_{D}(t)}{d t}\right]$ \\
\hline 11 & Maximum rate of normalized hysteretic energy & $P_{H, \text { max }}=\frac{1}{f_{y} x_{y}} \max _{0 \leq t \leq t_{f}}\left[\frac{d E_{H}(t)}{d t}\right]$ \\
\hline
\end{tabular}


Table 2: Information on past recorded ground motion records for a firm soil site

\begin{tabular}{|c|c|c|c|c|c|c|c|c|}
\hline $\begin{array}{l}\text { Earthquake } \\
\text { date }\end{array}$ & Magnitude & $\begin{array}{c}\text { Epic. Dist. } \\
(\mathrm{km})\end{array}$ & $\begin{array}{c}\text { Comp- } \\
\text { onent }\end{array}$ & $\begin{array}{l}\text { PGA } \\
\left(\mathrm{m} / \mathrm{s}^{2}\right)\end{array}$ & $\begin{array}{l}\mathrm{PGV} \\
(\mathrm{m} / \mathrm{s})\end{array}$ & $\begin{array}{c}\text { PGD } \\
(\mathrm{m})\end{array}$ & $\begin{array}{l}\text { Energy }^{*} \\
\left(\mathrm{~m} / \mathrm{s}^{1.5}\right)\end{array}$ & Site \\
\hline Mamoth lakes & \multirow[t]{2}{*}{6.2} & \multirow[t]{2}{*}{1.5} & $\mathrm{~W}$ & 4.02 & 0.21 & 0.05 & 3.73 & \multirow[t]{2}{*}{ Convict Greek } \\
\hline 05.25 .1980 & & & $\mathrm{~S}$ & 3.92 & 0.23 & 0.05 & 4.01 & \\
\hline Loma prieta & \multirow[t]{2}{*}{7.0} & \multirow[t]{2}{*}{9.7} & $\mathrm{~W}$ & 3.91 & 0.31 & 0.07 & 3.82 & \multirow[t]{2}{*}{ Capitola } \\
\hline 10.18 .1989 & & & $\mathrm{~S}$ & 4.63 & 0.36 & 0.11 & 2.61 & \\
\hline Morgan hill & \multirow[t]{2}{*}{6.1} & \multirow{2}{*}{4.5} & S60E & 3.06 & 0.40 & 0.07 & 2.33 & \multirow[t]{2}{*}{ Halls valley } \\
\hline 04.24 .1984 & & & S30W & 1.53 & 0.30 & 0.02 & 1.64 & \\
\hline San Fernando & \multirow[t]{2}{*}{6.6} & \multirow[t]{2}{*}{27.6} & N69W & 3.09 & 0.17 & 0.04 & 2.07 & \multirow{2}{*}{$\begin{array}{l}\text { Castaic old } \\
\text { ridge }\end{array}$} \\
\hline 02.09.1971 & & & N21E & 2.66 & 0.28 & 0.10 & 2.47 & \\
\hline Parkfield & \multirow[t]{2}{*}{5.0} & \multirow[t]{2}{*}{9.1} & W & 2.88 & 0.44 & 0.01 & 1.33 & \multirow[t]{2}{*}{ Parkfield fault } \\
\hline 12.20.1994 & & & $\mathrm{S}$ & 3.80 & 0.10 & 0.01 & 1.74 & \\
\hline Caolinga & \multirow[t]{2}{*}{6.5} & \multirow[t]{2}{*}{30.1} & $\mathrm{~W}$ & 2.83 & 0.26 & 0.10 & 2.67 & \multirow[t]{2}{*}{ Cantua creek } \\
\hline 05.02 .1983 & & & $\mathrm{~N}$ & 2.20 & 0.26 & 0.10 & 2.14 & \\
\hline Northridge & \multirow[t]{2}{*}{6.7} & \multirow[t]{2}{*}{5.9} & S74E & 3.81 & 0.60 & 0.12 & 4.17 & \multirow[t]{2}{*}{ Canoga park } \\
\hline 01.17.1994 & & & S16W & 3.43 & 0.34 & 0.09 & 3.50 & \\
\hline Cape Mendocino & \multirow[t]{2}{*}{7.0} & \multirow[t]{2}{*}{5.4} & W & 3.25 & 0.45 & 0.15 & 2.44 & \multirow{3}{*}{$\begin{array}{l}\text { Petrolia } \\
\text { general }\end{array}$} \\
\hline 04.25 .1992 & & & $\mathrm{~S}$ & 2.89 & 0.24 & 0.08 & 2.31 & \\
\hline Westmorland & \multirow[t]{2}{*}{5.0} & \multirow[t]{2}{*}{6.6} & $\mathrm{E}$ & 4.35 & 0.33 & 0.11 & 3.26 & \\
\hline 04.26 .1981 & & & S & 3.54 & 0.44 & 0.15 & 3.25 & \multirow{3}{*}{$\begin{array}{l}\text { Westmorland } \\
\text { fire }\end{array}$} \\
\hline Imperial valley & \multirow[t]{3}{*}{6.4} & \multirow[t]{3}{*}{17.4} & S45W & 2.68 & 0.22 & 0.10 & 2.30 & \\
\hline 10.15 .1979 & & & N45W & 1.98 & 0.19 & 0.15 & 2.14 & \\
\hline & & & & & & & & Calexico fire \\
\hline
\end{tabular}

* $E=\left[\int_{0}^{\infty} \ddot{v}_{g}^{2}(t) d t\right]^{1 / 2} \quad$ (Arias 1970). 
Table 3: Nomenclature of constraint scenarios considered

\begin{tabular}{cl}
\hline Case & Constraints imposed \\
\hline 1 & Energy and PGA \\
2 & Energy, PGA, PGV and PGD \\
3 & Energy, PGA and UBFAS \\
4 & Energy, PGA, UBFAS and LBFAS \\
\hline
\end{tabular}

Table 4: Response parameters for alternative constraint scenarios $(\alpha=0.05, \zeta=0.03)$

\begin{tabular}{lllllll}
\hline Case & $x_{\max }(\mathrm{m})$ & $\mu_{\max }$ & $x_{p}(\mathrm{~m})$ & $N_{r v}{ }^{*}$ & $D I_{P A}$ & Damage status \\
\hline 1 & 0.47 & 4.65 & 0.07 & 60 & 1.15 & Total collapse \\
2 & 0.45 & 4.53 & 0.06 & 54 & 0.97 & Damaged beyond repair \\
3 & 0.41 & 4.14 & 0.07 & 49 & 0.72 & Damaged beyond repair \\
4 & 0.26 & 2.64 & 0.05 & 44 & 0.37 & Repairable damage \\
\hline
\end{tabular}

$* \frac{4}{N_{r v}=\text { number of yield reversals (see Table } 1 \text { ) }}$

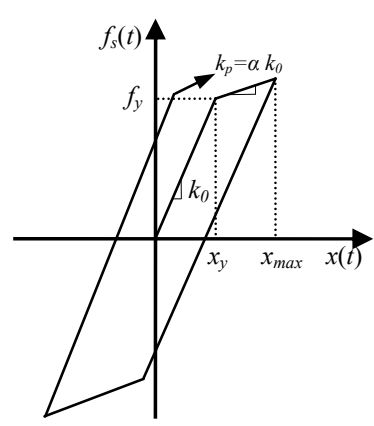

(a) Bilinear model

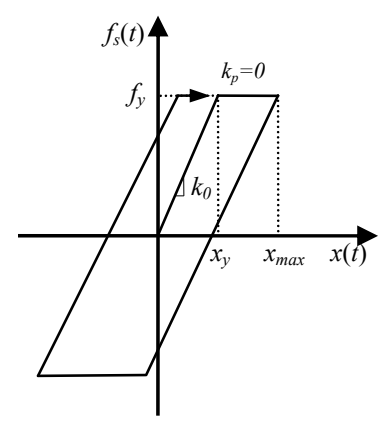

(b) Elastic-plastic model

Fig. 1: (a) Force-displacement relation for nonlinear materials 


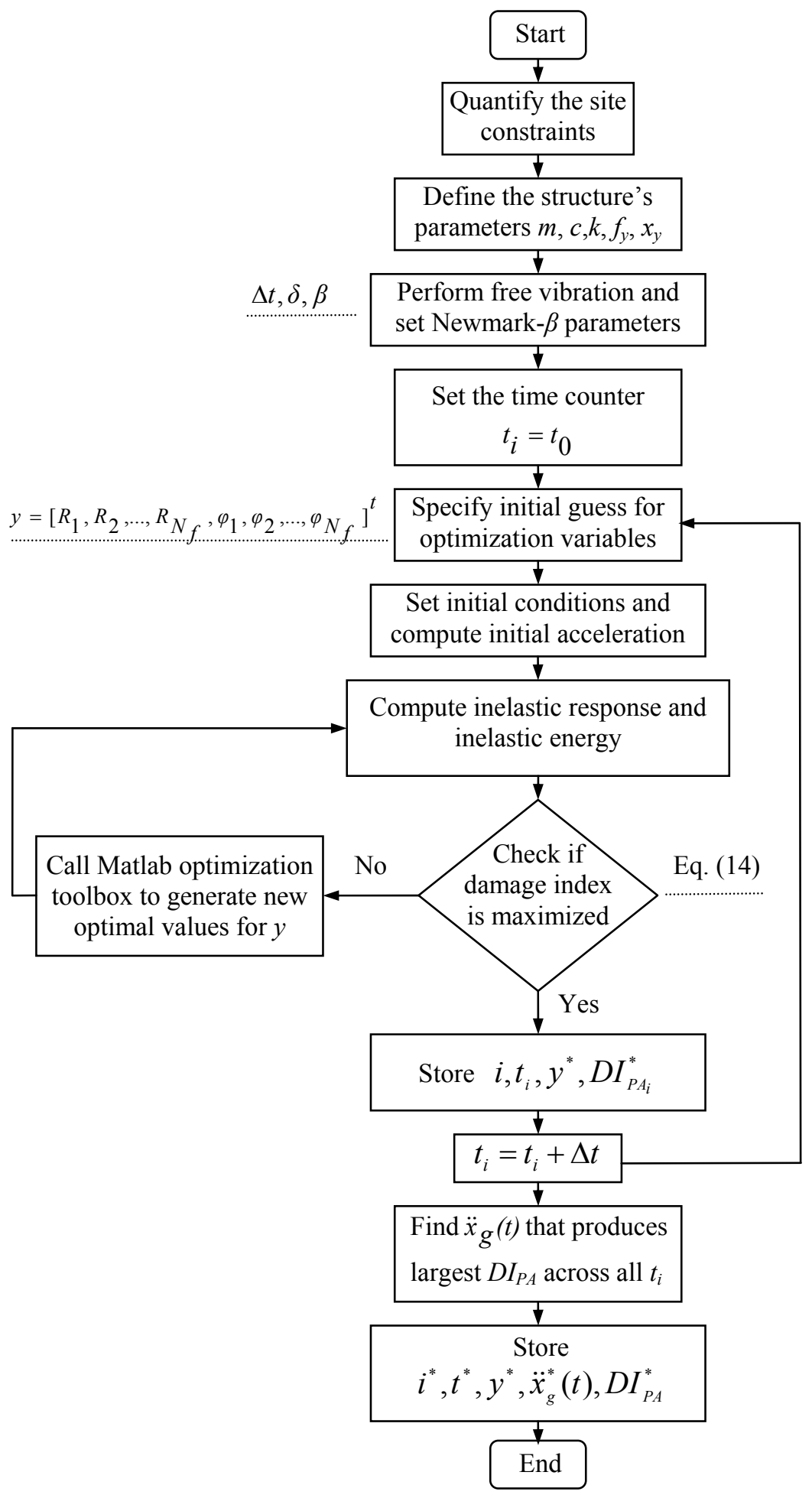

Fig. 2: Flowchart for deriving optimal earthquake loads 
(a)

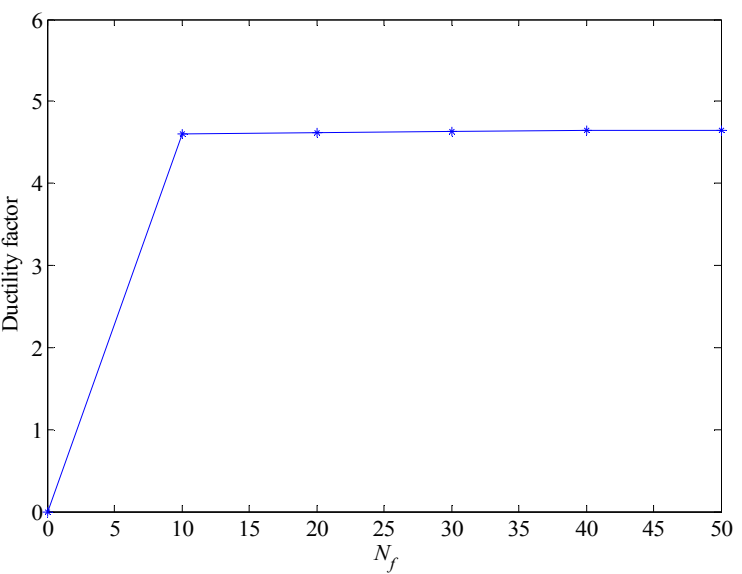

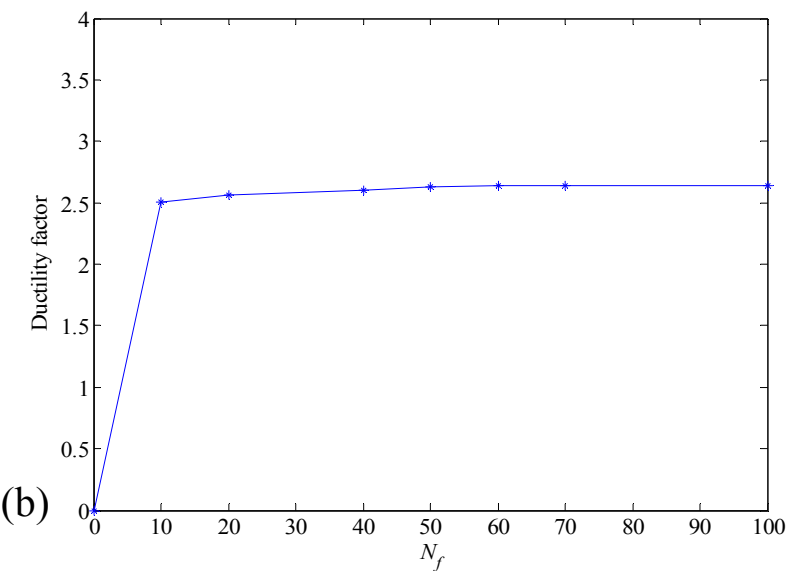

Fig. 3: Convergence of objective function in terms of frequency terms $N_{f}$ (a) Case 1 (b) Case 4

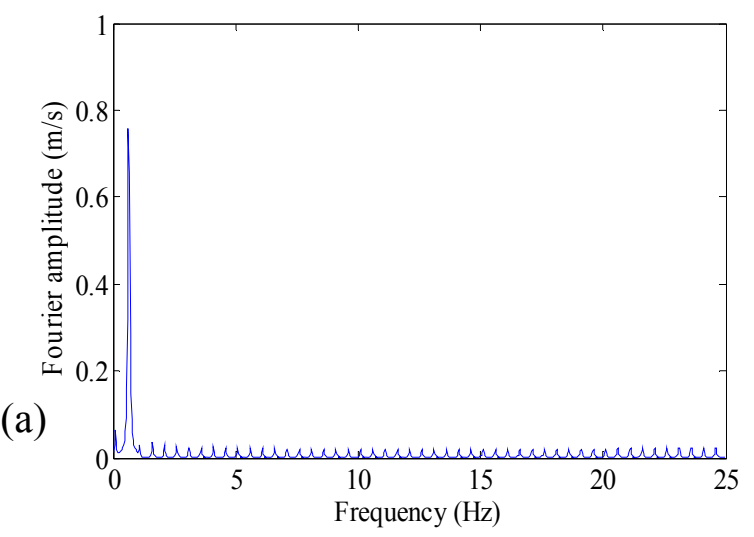

(b)
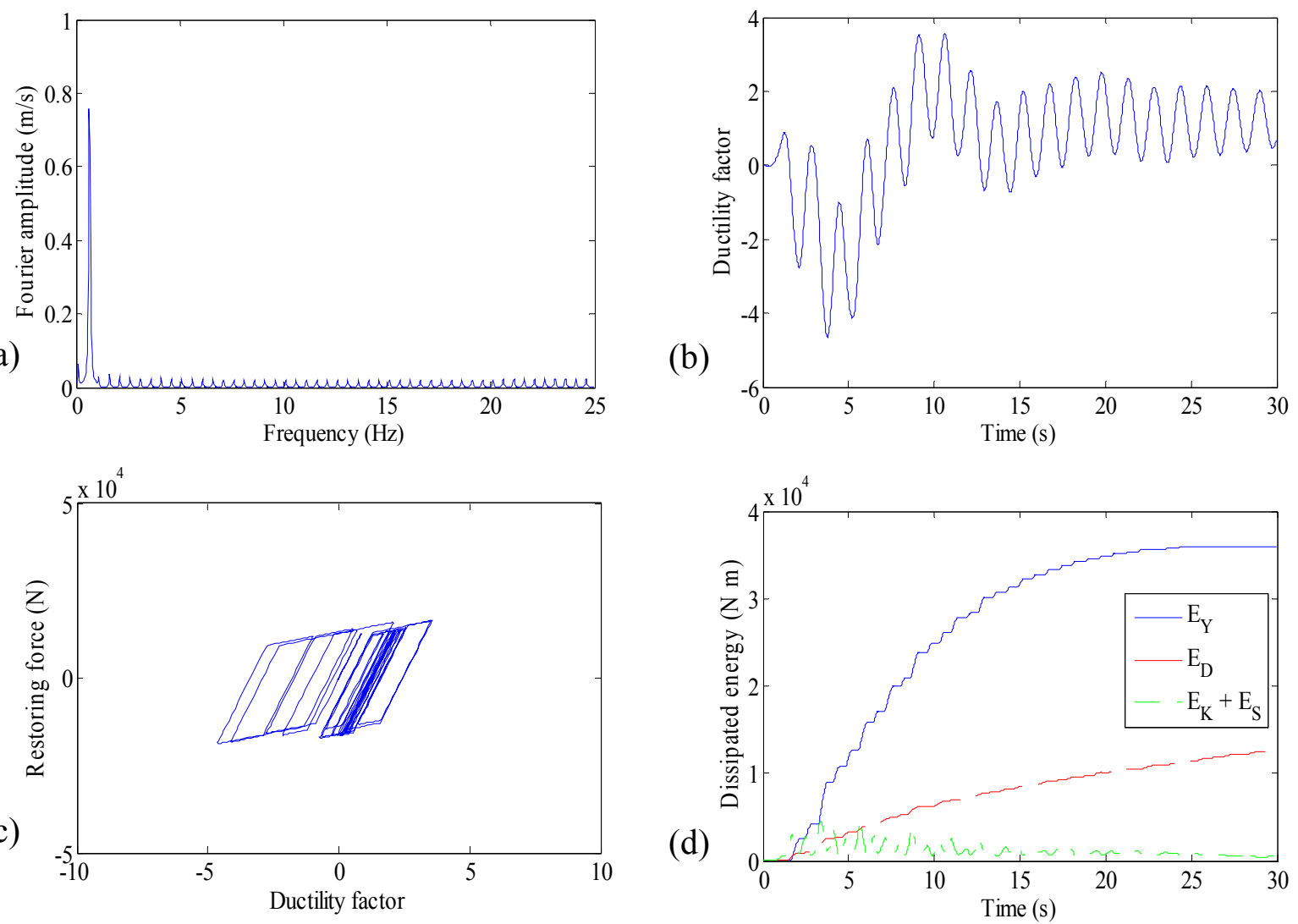

Fig. 4: Optimal earthquake input and associated structural responses for case 1 (a) Fourier amplitude of the ground acceleration (b) Normalized inelastic deformation (c) Hysteretic restoring force (d) Dissipated energy 

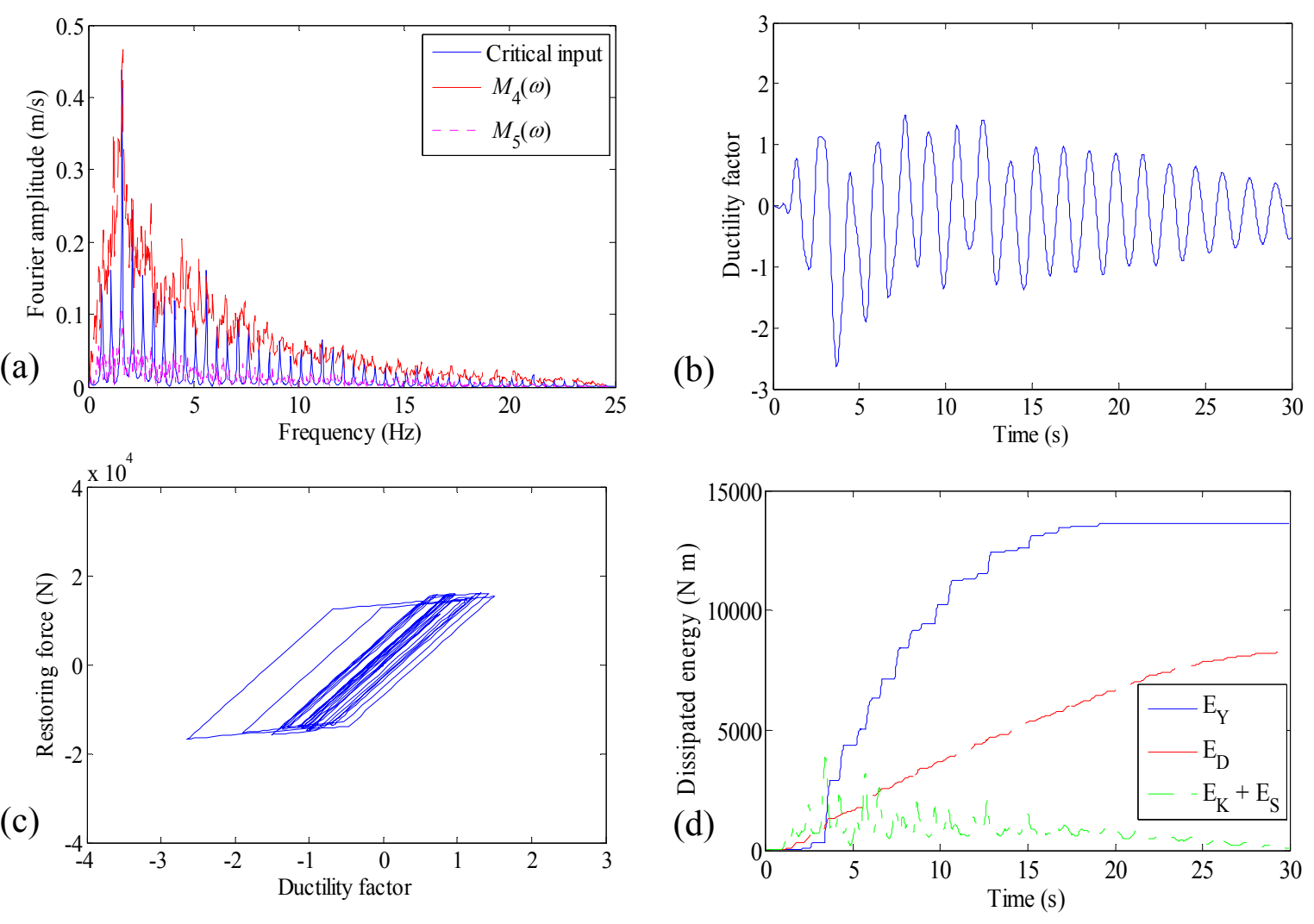

Fig. 5: Optimal earthquake input and associated structural responses for case 4 (a) Fourier amplitude of the ground acceleration (b) Normalized inelastic deformation (c) Hysteretic restoring force (d) Dissipated energy
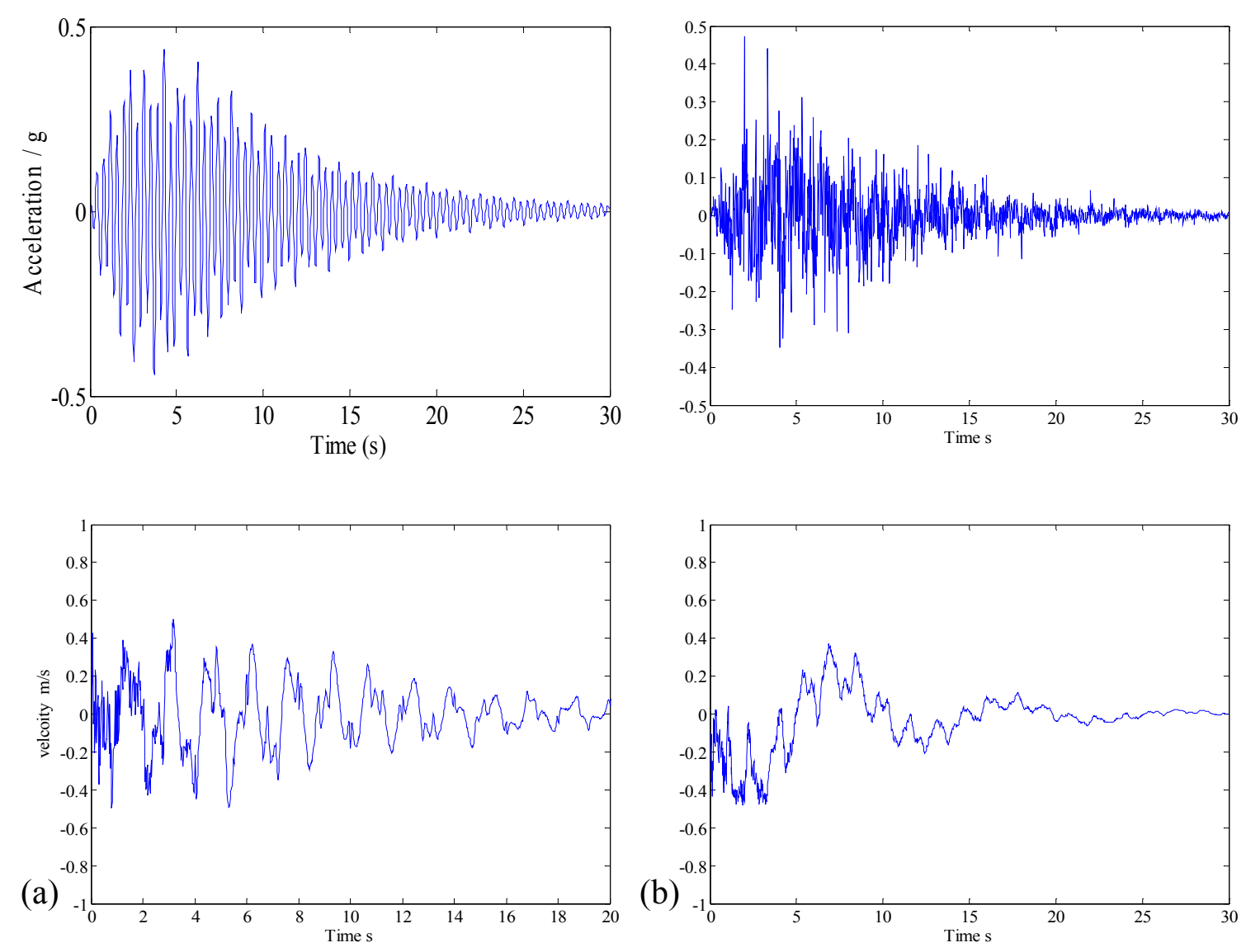

Fig. 6: Optimal earthquake acceleration and velocity (a) Case 1 (b) Case 4 

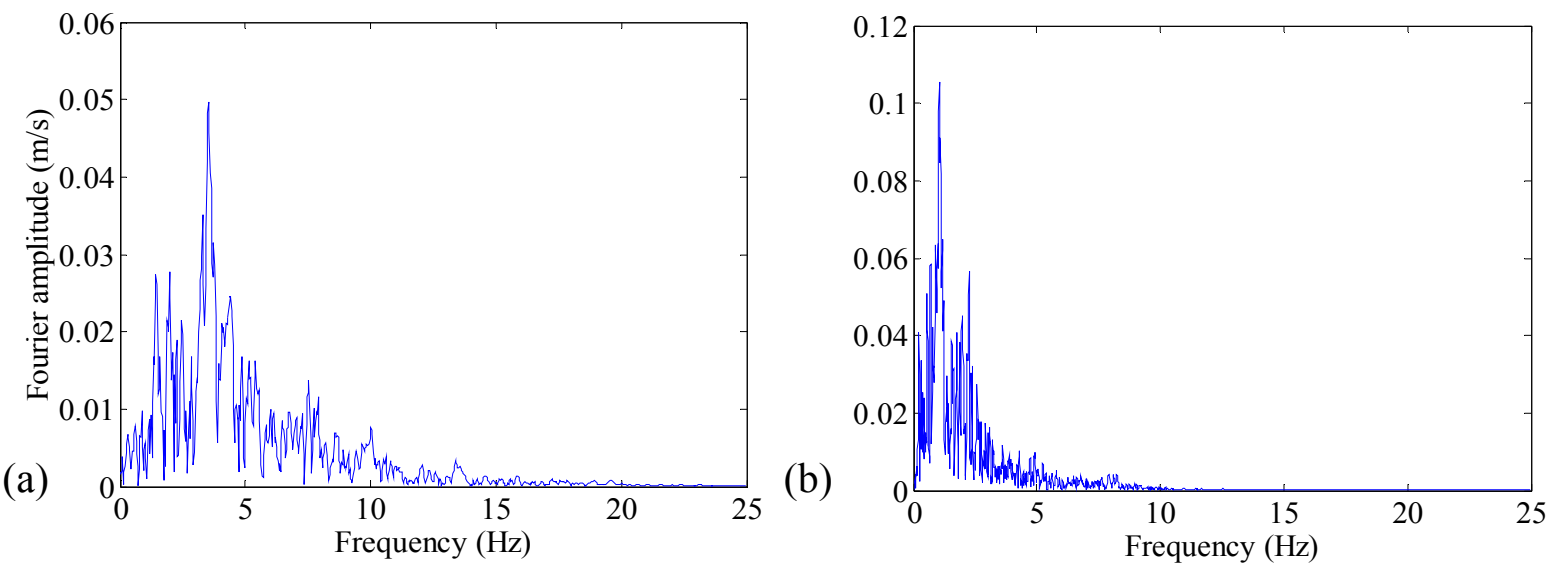

Fig. 7: Fourier amplitude of recorded earthquakes (a) San Fernando 1971 (b) Hyogoken-Nanbu 1995
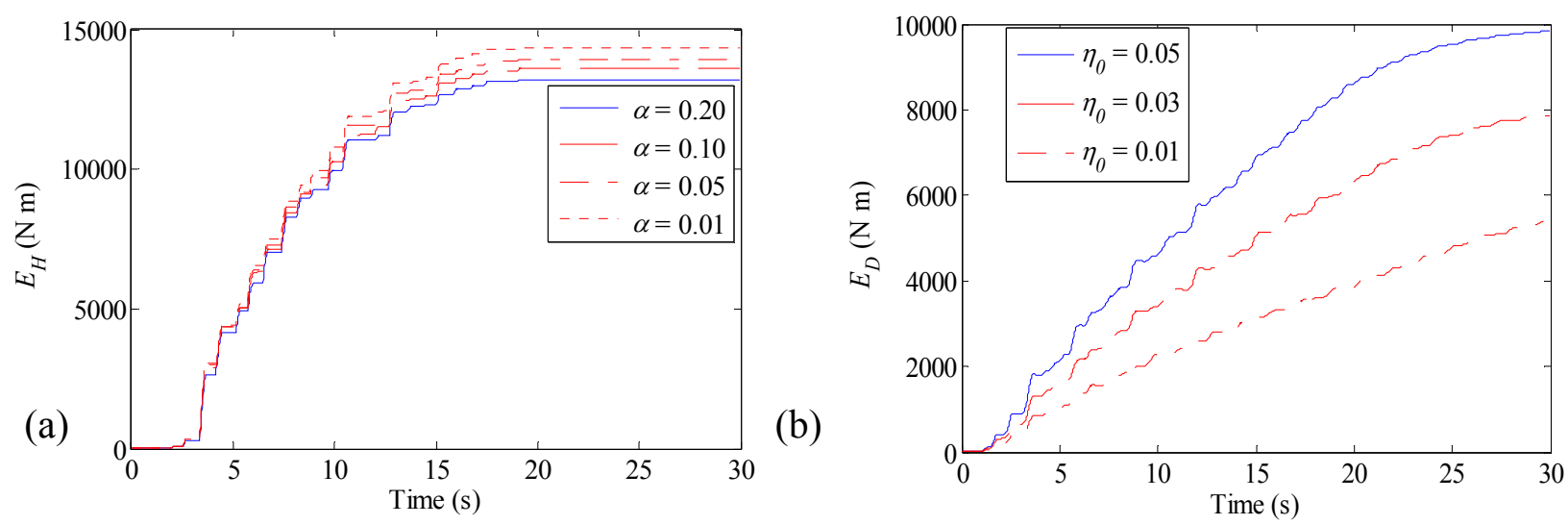

Fig. 8: (a) Effect of strain hardening ratio on dissipated yield energy (b) Effect of damping on dissipated damping energy

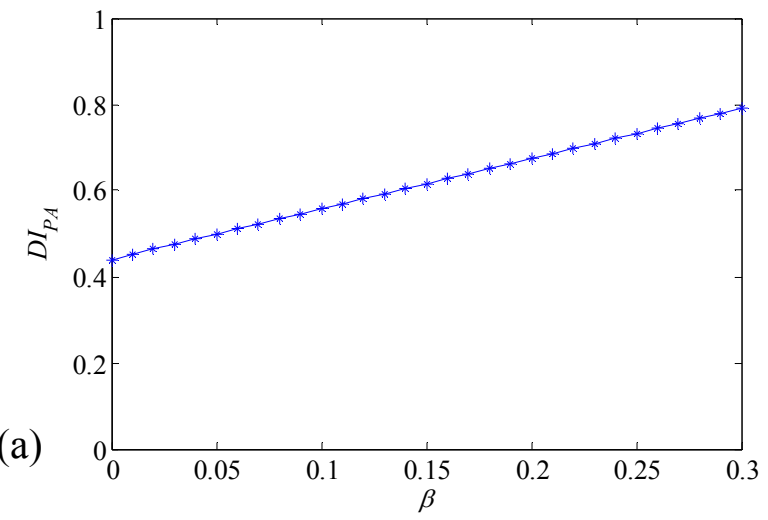

(b)

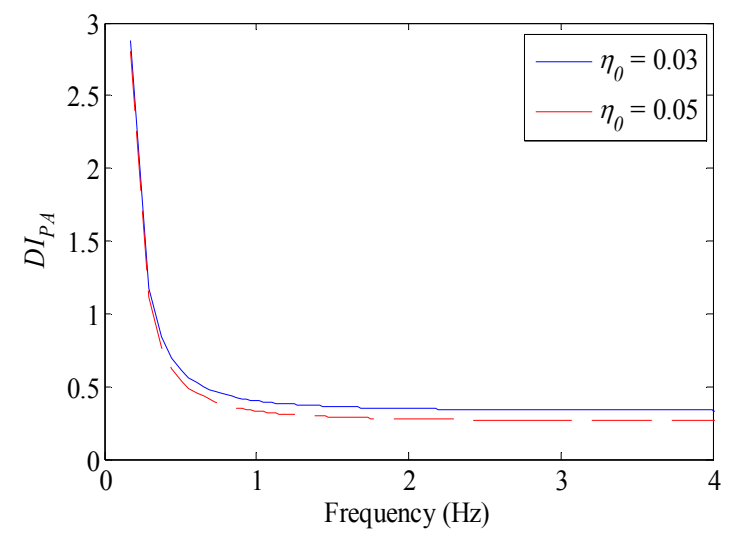

Fig. 9: (a) Effect of the value of $\beta$ on the damage index (b) damage spectra for inelastic SDOF buildings 